\title{
Polyostotic Fibrous Dysplasia in a Child with Bone Fractures and Neuropsychiatric Symptoms, Case Report
}

\author{
Hala A Al Shaikh* \\ Senior Consultants Pediatric Endocrinologist, Department of Pediatrics, Muscat \\ Hospital, Oman \\ *Corresponding author: Dr Hala Al Shaikh, Senior Consultants Pediatric \\ Endocrinologist, Department of Pediatrics, Muscat Hospital, Bowsher, Muscat, Oman, \\ Email: hal_doc@yahoo.com
}

\section{Case Report \\ Volume 3 Issue 1}

Received Date: February 10, 2019

Published Date: February 20, 2019

DOI: $10.23880 /$ jobd- 16000171

\section{Abstract}

Fibrous dysplasia of the bone in children is a rare, genetic, heterogeneous disorder, associated with extra-skeletal manifestations in the McCune Albright Syndrome. It results from a post-zygotic activating mutation in the (GNAS) gene coding for (Gs alfa) protein. This leads to replacement of the lamellar bone with under-mineralized fibrous tissue, presenting clinically with limping, pain, and pathological fractures.

Objective: To demonstrate the clinical course, challenges and treatment of a child with polyostotic fibrous dysplasia presenting with limping, extra skeletal manifestations, neuropsychiatric symptoms and bone fractures.

Method: The clinical information and lab results were obtained directly from the mother and the computerized medical records at the treating hospitals. Genetic analysis was done at Washington University School of Medicine, USA. Informed publication consent was obtained from the parents.

Results: The child presented at the age of 3years with limping and was found to have polyostotic fibrous dysplasia and café au lait spot. Later on, he developed neurological symptoms. He had bone fractures in the proximal femur, requiring surgical intervention. Bone pain and frequency of fractures improved after Zoledronate injections. Blood genetic analysis of the GNAS-gene was negative.

Conclusion: Polyostotic fibrous dysplasia is a rare cause of limping and recurrent pathological fractures in children. Medical treatment with Biphosphanate injections can positively affect the clinical course of the disease. A negative blood genetic analysis of the GNAS gene does not exclude the McCune Albright Syndrome, and indicates analysis from the affected tissue. Neuropsychiatric symptoms may manifest with fibrous dysplasia without any endocrine involvement.

Keywords: Fibrous dysplasia; McCune Albright Syndrome; Neuropsychiatric symptoms; Bone fractures; Surgical intervention; Zoledronate injection 


\section{Journal of Orthopedics \& Bone Disorders}

\section{Introduction}

Fibrous dysplasia of the bone in children is a rare sporadic, genetic disorder. It can be monostotic or polyostotic and may be associated with extra-skeletal manifestations in the Mc Cune Albright Syndrome. It results from a post-zygotic activating mutation in the (GNAS) gene coding for the stimulatory (Gs alfa) protein, resulting in increased intracellular levels of cAMP, leading to replacement of the lamellar bone with undermineralized fibrous tissue and is associated clinically with pain, bone deformities and pathological fractures. Extra skeletal manifestations associated with fibrous dysplasia in the McCune Albright Syndrome include: café au lait spots, precocious puberty, autonomous hyper functioning of the endocrine system, phosphaturia, hepatic involvement, cardiac involvement and neuropsychiatric symptoms.

\section{Objective}

The aim of this paper is to demonstrate the clinical course, challenges and treatment of a child with polyostotic fibrous dysplasia presenting with limping, extra skeletal manifestations, neuropsychiatric symptoms and bone fractures.

\section{Case Report}

I.B, currently 6 years old, is a product of nonconsanguineous marriage; born to a G2P1 mother, four days overdue, with a birth weight of $3.6 \mathrm{~kg}$. There were no pre/postnatal complications. He sat at 5 months, started crawling at 10 months and walked by 12 months. Hearing and vision were normal. He was first seen in the Pediatric Endocrine Clinic at 3 years of age, referred from the Orthopedic Clinic for limping, to be investigated for metabolic bone disease. His X-rays showed fibrous dysplasia of the humerus, femur and tibia on the right side.

\section{Family History}

Currently the mother is 29 years of age with no health problems. She attained puberty at 10 years. The father is 31 years old and has high total cholesterol level. He attained puberty at 12 years. The subject's elder brother is 7 years of age and has chronic constipation of unknown etiology and the younger brother is 3 years old and he is healthy. The maternal grandfather has high blood pressure, high total blood cholesterol level and T2DM. The maternal uncle has high BP. The paternal grandmother has Addison's disease. The Paternal aunt has mitral valve prolapse and dysautonomia.

\section{Physical Examination and Investigation}

Physical examination of the child revealed a weight of $14.6 \mathrm{~kg}$, falling on the 50th centile and a height of $95.5 \mathrm{cms}$ falling on the 75 th centile. There was leg length discrepancy; the right leg being shorter than the left. A café au lait spot around one $\mathrm{cm}$ in diameter was noticed on the abdomen just below the umbilicus. The rest of the physical examination was within normal limits. Investigations were done, the results can be seen in Table 1.

\begin{tabular}{|c|c|}
\hline Serum Sodium & $131 \mathrm{mmol} / \mathrm{L}$ \\
\hline Serum Potassium & $4.4 \mathrm{mmol} / \mathrm{L}$ \\
\hline Serum Chloride & $102 \mathrm{mmol} / \mathrm{L}$ \\
\hline Serum Urea & $4.8 \mathrm{mmol} / \mathrm{L}$ \\
\hline Serum Creatinine & $18.3 \mathrm{mmol} / \mathrm{L}$ \\
\hline $8 \mathrm{AM}$ Cortisol & $270 \mathrm{nmol} / \mathrm{L}$ \\
\hline ACTH & $33.9 \mathrm{ng} / \mathrm{ml}$ \\
\hline DHEAS & $18 \mathrm{ng} / \mathrm{ml}$ \\
\hline LH & $<0.1 \mathrm{IU} / \mathrm{L}$ \\
\hline FSH & $0.168 \mathrm{IU} / \mathrm{L}$ \\
\hline Testosterone & $<0.13 \mathrm{nmol} / \mathrm{L}$ \\
\hline Serum Ca (corr.) & $2.5 \mathrm{mmol} / \mathrm{L}$ \\
\hline Serum Phosphate & $1.75 \mathrm{mmol} / \mathrm{L}$ \\
\hline Alkaline Phosphatase & $325 \mathrm{U} / \mathrm{L}$ \\
\hline 25 (OH) Vit D & $18.6 \mathrm{ng} / \mathrm{dl}$ \\
\hline Prolactin & $206 \mathrm{mU} / \mathrm{L}$ \\
\hline TSH & $1.64 \mathrm{uIU} / \mathrm{L}$ \\
\hline FT4 & $1.09 \mathrm{ng} / \mathrm{dL}$ \\
\hline IgA & $1.38 \mathrm{~L} / \mathrm{L}$ \\
\hline ATT & $<5 \mathrm{U} / \mathrm{mL}$ \\
\hline
\end{tabular}

Table 1: Lab Investigation Results.

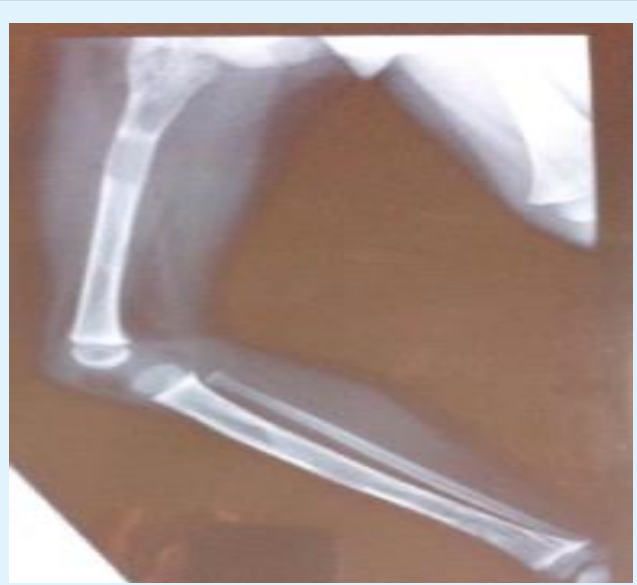

Figure 1: X-ray of the lower limb showing FD of the proximal femur and tibia. 


\section{Journal of Orthopedics \& Bone Disorders}

Ultrasound of the abdomen and testes showed normal abdominal structures. The right testes: $0.9 \times 1.8 \mathrm{~cm}$ was slightly larger than the left: $0.7 \times 1.7 \mathrm{~cm}$. The epididymis was equal on both sides, $0.3 \times 0.5 \mathrm{~cm}$. Bone Age corresponded to the chronological Age of 3 years.

\section{Clinical Course and Management}

In view of vitamin $D$ falling in the insufficient range, he was started on Vitamin D supplement 800 units per day. He was seen by the orthopedic surgeon who confirmed the disparity in length between the two legs, the right 0.7 $\mathrm{cm}$ shorter than the left, resulting in Tendon Achilles contracture. He had normal foot arch and examination of the back was normal. Stretching exercises were advised and wearing a shoe rise on the right.

He was also seen by the ophthalmologist and ENT specialist and referred to the speech therapist for stuttering. He had no hearing impairment and his eye checkup was normal. His stuttering improved after a few sessions with the speech therapist.

At 3 years and eight months of age, he developed a hairline fracture in the proximal 3rd of the femur when a child fell on him while playing at school. He presented with inability to bear weight and restriction of abduction on the right side. X-rays of the lower limb showed fibrous dysplasia involving the proximal half of the femur and upper one third of the tibia. A fracture was seen in the proximal third of the femur. It was treated with a long leg slab. He was walking with the slab with no complaints and showed callus formation within two weeks. Complete healing was seen in six weeks and the slab was removed.

At around 4years of age, the mother noticed that he had jerky movements during sleep. He was seen by a pediatric neurologist who diagnosed Benign Myoclonic Jerks and treatment with drugs was recommended but the mother refused. He also complained of abdominal pain, screening for Celiac disease came as negative.

At 4years and five months of age, he had another fracture in the upper third of the right femur after falling down. The fracture had a displacement of forty-five degrees and was managed with an intramedullary rod. He was also found on X-ray to have femur head varus malrotation with flexion deformity. A DEXA Scan was requested which showed a lumbar spine Z- score of -1.1 and whole body Z-score of -0.8 . His limp had much improved with the shoe rise. In view of having two fractures in a period of less than one year, and to reduce bone pain, he was given Zoledronate injection (0.05 $\mathrm{mg} / \mathrm{kg}$ ) with no complications.

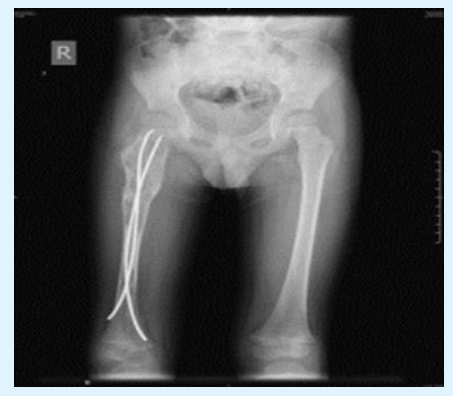

Figure2: X-ray showing the right femur with intramedullary rod.

One year later, he was operated in the USA for the femur head mal-rotation by placing a plate and flexible pins in the Rt femur. Wedge resection and bone grafting of the fibro dysplastic part of the femoral head was also done. His gait much improved and he sustained a mild limp without the shoe-rise which was more noticeable on running. He received a second Zoledronate injection $(0.05$ $\mathrm{mg} / \mathrm{kg}$ ), 6 months after the first injection. His sleeping at night became better and the frequency of the jerky movements became less. He also had targeted nextgeneration sequencing on a peripheral blood sample of the GNAS gene which came as negative. However, McCune Albright Syndrome could not be excluded with this result, and future testing of the soft tissue surrounding an affected bone lesion was planned.

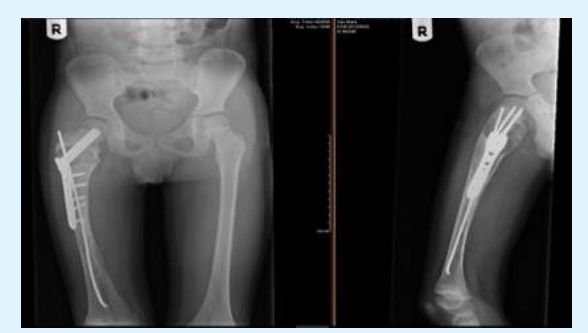

Figure 3: X-ray of the right femur with a slab and nail.

On his last visit to the pediatric Endocrine clinic at 5 years and nine months of age, he was doing fine with no bone pain (assessed by Wong-Baker Faces Pain Rating Scale) or additional fractures. A third Zoledronate injection was administered. His growth was satisfactory with a height of $111.5,\left(75^{\text {th }}-90^{\text {th }}\right)$ and a weight of $18.7 \mathrm{~kg}$, $\left(25^{\text {th }}-50^{\text {th }}\right)$. 


\section{Journal of Orthopedics \& Bone Disorders}

\section{Discussion}

Fibrous dysplasia (FD) of the bone in children is a rare non-inheritable genetic disorder with an incidence rate of 1 in 15,000 - 30,000 per year. It can be monostotic (MFD) in $70 \%$ of the cases, or polyostotic (PFD), $30 \%$ of the cases [1]. It may be associated with extra-skeletal manifestations in the McCune Albright Syndrome which is classically defined by the triad of PFD, café au lait skin hyperpigmentation and hyper functioning endocrinopathies: hyperthyroidism, precocious puberty, Cushing Syndrome, and phosphaturia [2]. Other less common associations include: gastrointestinal, hepatic or cardiac involvement and neuropsychiatric manifestations [3]. FD may also be associated with myxomas of the skeletal muscle in the Mazabraud Syndrome [4]. Our patient had one café au lait spot on the trunk below the umbilicus, which was first noticed at around 3 years of age but disappeared 2 and a half years later and was not detected even with wood light examination. This could have been on skin that was pulled in as the naval got deeper. He also had neuropsychiatric symptoms in the form of stuttering of speech and myoclonic jerks while sleeping. The stuttering improved with speech therapy and the myoclonic jerks became much less with no medication. Neuropsychiatric symptoms have been described in the McCune Albright Syndrome in the form of mental sub normality, speech apraxia, learning disorders, and global developmental delays, [3]. In a cohort of 140 patients (1-24 years of age) with the McCune Albright Syndrome, 9\% had neuropsychiatric manifestations, out of which $44 \%$ of the subjects had Cushing Syndrome, [5]. This could indicate that high levels of cortisol negatively affect brain development. In our patient, there was no Cushing Syndrome; the etiology of the symptoms could have been psychological or as a result of affection of the nervous system, or both. In addition, there was a family history of Addison's disease, which could indicate a familial tendency to neuropsychiatric manifestations [6]. McCune Albright Syndrome results from a post-zygotic activating mutation in the gene (GNAS) on chromosome 20, coding for stimulatory G-protein (Gs alfa); decreasing the GTPase activity and resulting in increased intracellular levels of cAMP (6). In our patient, genetic analysis of the GNAS gene in the blood came as negative. However, mutation analysis on the tissue surrounding the affected bone tissue is considered, as GNAS mutations represent different patterns of somatic mosaicism [7-9].

The proximal femur is the most commonly reported site of pathological fractures in individuals with PFD in association with the 'shepherd crook deformity', as a result of the weight bearing forces acting on the lower extremity. The majority of fractures occur in the first decade of life [10]. Surgical approaches to treatment of fibrous dysplasia of the femur should include treatment and prevention of pathological fracture as well as correction of deformities [11]. Our subject had 2 pathological fractures in the proximal end of the right femur in less than a year; a hair line fracture at 3 years and 8 months of age and a 45 degrees fracture at 4 years and 5 months. This is considered a relatively young age for fracture development in FD [12]. The first fracture was treated with a slab for 6 weeks and the second was treated with an intramedullary nail and rod. One year later, he was re-operated in the USA by angled plate insertion and prophylactic pinning. For the femoral head mal-rotation, bone grafting of the fibro dysplastic part of the femoral head and wedge resection was done. He is now freely mobile and pain free. Either angled plate or intramedullary rod with nail can be used to treat fibrous dysplasia of the proximal femur. Both modalities give good results in regards to function, pain, and fracture prevention. However, in the Majoor and Leithner cohort, 2 out of 27 patients treated with angled plate had fracture distal to the plate and 7 experienced pain due to traction of the iliotibial tract, necessitating removal of the plate. Allogeneic grafting has a place, in selected cases, in the management of impending fractures and pain due to FD of the proximal femur [13]. The risk of failure or recurrence of deformity or fracture is high in young and growing patients and the need for revision surgery in such cases with a customized device providing stability and preventing further deformation of the femur should be considered.

Our patient received 3 six-monthly injections of Zoledronate for the known advantage of Biphosphanates in the management of fibrous dysplasia in terms of functional improvement, increased bone mineral density and reduced bone pain and bone turnover markers $[14,15]$. However, no refilling of the osteolytic lesions on radiography was observed $[16,17]$. Vigilant follow up and treatment focused on maintaining hip strength and range of motion and correcting leg length discrepancies and hip deformities at a young age is mandatory to preserve ambulatory function [18].

Our patient did well at school and was quite happy and emotionally stable during his clinic visits, however, no formal Quality of Life assessment was performed. Bas et al in their study on determinants of impaired quality of life in patients with fibrous dysplasia found that there was impairment in all the quality of life parameters except 'Mental health' and 'Role emotional' [19]. 


\section{Journal of Orthopedics \& Bone Disorders}

\section{Conclusion}

Polyostotic fibrous dysplasia is a rare cause of limping and recurrent pathological fractures in children. Medical treatment with Biphosphanate injections can positively affect the clinical course of the disease. A negative blood genetic analysis of the GNAS gene does not exclude the McCune Albright Syndrome, indicating analysis from the affected tissue. Neuropsychiatric symptoms may manifest with fibrous dysplasia with or without any endocrine involvement.

\section{References}

1. Report of the NORD (2017) Fibrous Dysplasia.

2. Report of NORD (2017) McCune Albright Syndrome.

3. Collins MT, Singer FR, Eugster E (2012) McCuneAlbright Syndrome and the extraskeletal manifestations of fibrous dysplasia. OJRD 7(S1): 1-14.

4. Munksgaard P, Salkus G, Iyer V, Vincents Fisker R (2013) Mazabrauds Syndrome, Case Report and Literature Review. ACTA Radiologica Short Reports 2: 8-12.

5. Brown RJ, Kelly MH, Collins MT (2010) Cushing Syndrome in the McCune Albright Syndrome. JCEM 95(4): 1508-1515.

6. Anglin RE, Rosebush PI, Mazurek MF (2006) The Neuropsychiatric Profile of Addison's disease: Revisiting a Forgotten Phenomenon. J Neuropsychiatry Clin Neurosci 18(4): 450-459.

7. Shenker A, Weinstein LS, Sweet DE, Spiegel AM (1994) An activating Gs alpha mutation is present in fibrous dysplasia of bone in the McCune-Albright syndrome. JCEM 79: 750-755.

8. Bianco P, Riminucci M, Majolagbe A, Kuznetsov SA, Collins MT, et al. (2000) Mutations of the GNAS1 gene, stromal cell dysfunction and osteomalacic changes in non- McCune Albright fibrous dysplasia of the bone. J Bone Miner Res 15(1): 120-128.

9. Lumbroso S, Paris F, Sultan C (2004) Activating Gsalpha mutation analysis of 113 patients with signs of McCune Albright Syndrome. A European Collaborative Study 89(5): 2107-2113.

10. Ippolito E, Bray E, Corsi A, Maio F, Exner UG, et al. (2012) Natural history and treatment of fibrous dysplasia of bone: A multicenter clinicopathologic study promoted by the European Paediatric Orthopaedic Society. J Paediatr Orthop 12(3): 155177.

11. Arabella IL, Chebli C, Kushner H, Chen CC, Kelly MH, et al. (2004) Fracture incidence in polyostotic fibrous dysplasia and the McCune Albright Syndrome. J Bone Miner Res 19(4): 571-577.

12. Kushare IV, Colo D, Bakhshi H, Dormans JP (2014) Fibrous Dysplasia of the proximal femur: Surgical management options and outcomes. J Child's Orthop 8(6): 505-511.

13. Majoor B, Leithner A, Sande M, Natasha M (2018) Individualised approach to the surgical management of fibrous dysplasia of the proximal femur. OJRD 13: 72-84.

14. Isaia GC, Lala R, Defilippi C, Matarazzo P, Andreo M, et al. (2002) Bone Turnover in children and Adolescents with McCune Albright Syndrome treated with Pamidronate for Bone Fibrous Dysplasia. Calcif Tissue Int 71(2): 121-128.

15. Raj N, Krishnan V, Sakthivel R (2010) Treatment of Fibrous Dysplasia with Zoledronic Acid Infusion, Case Report, Review of Literature and Future Prospectives. Webmed Central Orthopaedics 1(11): WMC001206.

16. Plotkin H, Rauch F, Zeitlin L, Munns C, Travers R, et al. (2003) Effect of Pamidronate Treatment in Children with Polyostotic Fibrous Dysplasia of the Bone. JCEM 88(10): 4569-4575.

17. Lala R, Matarazzo P, Bertelloni S, Buzi F, Rigon F, et al. (2007) Pamidronate Treatment of Fibrous Dysplasia in nine Children with McCune Albright Syndrome. ACTA Paediatrica 89(2): 188-193.

18. Paul S, Gabor L, Rudzinski S, Giovanni D, Boyce AM, 7et al. (2014) Disease Severity and Functional Factors associated with walking Performance in Polyostotic Fibrous Dysplasia. Bone 60: 41-47.

19. Majoor B, Andela C, Bruggemann J, van de Sande MAJ, Kaptein AA, et al. (2017) Determinants of impaired Quality of Life in Patients with Fibrous Dysplasia. OJRD 12(1): 80-88. 